\title{
Retraction Note: Enhancement of bio-sludge gravitational thickening with weak ultrasound
}

\author{
P. Zhang $\cdot$ T. Wan $\cdot$ G. Zhang
}

Published online: 19 June 2012

(C) CEERS, IAU 2012

Erratum to: Int. J. Environ. Sci. Technol. (2012)

9:287-296

DOI 10.1007/s13762-012-0023-0

The publisher and the editors of the International Journal of Environmental Science and Technology hereby retract the article entitled "Enhancement of bio-sludge gravitational thickening with weak ultrasound" by P. Zhang, T. Wan and G. Zhang, which was mistakenly published for a second time in International Journal of Environmental Science and Technology.

The original citable article can be found under DOI 10.1007/s11783-011-0368-5.

The online version of the original article can be found under doi:10.1007/s13762-012-0023-0.

\section{P. Zhang}

School of Environment Science and Engineering,

Beijing Forestry University, 65 Qinghuadong Road,

Beijing 100083, China

T. Wan · G. Zhang ( $₫)$

State Key Laboratory of Urban Water Resource

and Environment, Harbin Institute of Technology,

73 Huanghe Road, Harbin 150090, China

e-mail: zgm200@126.com 